\title{
Veinte años de estudios sobre la autotraducción: una entrevista con el profesor Julio-César Santoyo
}

\author{
Rainier Grutman \\ rgrutman@uottawa.ca \\ https://orcid.org/0000-0002-5947-5751 \\ School of Translation and Interpretation, University of Ottawa, Canadá
}

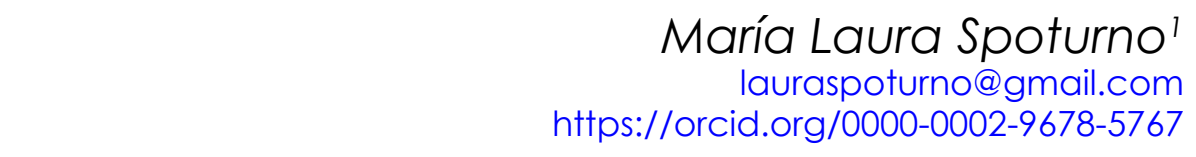

Universidad Nacional de La Plata; IdIHCS, UNLP, Consejo Nacional de Investigaciones Científicas y Técnicas, Argentina

Rainier Grutman y Maria Laura Spoturno: En los últimos veinte años, su labor en la historiografía de la autotraducción en Occidente ha sido destacadísima. ${ }^{2}$ Quisiéramos consultarle por su primer encuentro con un texto autotraducido. ¿En qué circunstancias descubrió la autotraducción y qué significó ese hallazgo para usted como traductor y como estudioso de la traducción? En su vasta experiencia como investigador de la autotraducción, ¿cuál ha sido el caso de autotraducción más sorprendente?

Julio César Santoyo: Yo comencé a interesarme por muy distintas facetas de la traducción (teóricas, prácticas, bibliográficas, históricas, contrastivas, etc.) allá por los años 70 y primeros 80 del pasado siglo: traducciones inglesas del Lazarillo de Tormes, primeros traductores inglés-español y viceversa, el translema o unidad de traducción, la traducción como técnica narrativa, versiones teatrales y su tipología, análisis de la labor traductora de Unamuno, Moratín, Azaña, etc. Cuando vuelvo ahora la vista atrás he de reconocer que todo lo que por entonces sonara a traducción me interesaba, y me interesaba mucho, pero sin que en ninguna parte de ese todo llegara yo hasta el fondo, salvo quizá en el caso del Lazarillo inglés, y tras él en el de la historia de la traducción, en particular la de la Península Ibérica, ya en los años 90. Pero al margen de estos dos temas, era tan dilatado el panorama traductológico que seguía abriéndose ante mí que sin método ni continuidad yo abordaba hoy este punto, los calcos como forma de traducción, por ejemplo, y mañana otro completamente distinto, como podría ser, y de hecho fue, el léxico pseudoespañol en traducciones.

1 Investigación financiada por la Agencia Nacional de Promoción Científica y Tecnológica [РіCт 2017-2942], el Consejo Nacional de Investigaciones Científicas y Técnica y la Universidad Nacional de La Plata [H/825 2017-2021], Argentina.

2 Al final de la entrevista, se encuentra una bibliografía completa de los trabajos publicados por el profesor Santoyo acerca del tema de la autotraducción (ver Apéndice). 
Así hasta que el destino quiso que en abril del año 2000 diera yo en la Universidad del País Vasco, en un congreso sobre literatura chicana, una conferencia que trataba precisamente de "Literatura chicana y traducciones de autor". Fue un primer encuentro con la autotraducción, muy a tientas todavía, pero fue suficiente, porque durante la preparación de la charla comprobé que por aquellas fechas (repito lo que en entonces, abril de 2000, dije) la autotraducción era "una parcela absolutamente menor en el ámbito de la traductología, un rincón olvidado, silenciado, obviado, ni siquiera mencionado por los más prestigiosos estudios y especialistas. Los índices de las obras de Newmark, Susan Bassnett, Steiner, Nida, Larson, Douglas Robinson o Wilss, por sólo citar algunos, apenas nada dicen de la autotraducción".

Sin dejar de lado mi otra gran parcela de interés, la historia de la traducción, mi rumbo investigador cambió radicalmente a partir de aquel primer encuentro, con el resultado de que a una y a otra, a la historia de la traducción y a la autotraducción, he dedicado la mayor parte de los últimos veinte años de mi vida académica, espero que con algún fruto, que ojalá sea el más importante para un investigador: el de haber abierto caminos por donde otros puedan transitar y llegar aún más lejos.

Doy por supuesto que cada autotraducción es distinta (dudo que en esta parcela haya patrones comunes), porque cada autotraducción es hija de un momento concreto en el tiempo, de unas circunstancias textuales distintas y de la distinta personalidad de cada autor-traductor. Todo ello impide, creo yo, o dificulta, la selección de un texto autotraducido en particular. Aun así, el autotraductor (y su obra) que por diversos motivos más me ha llamado la atención es Rabindranath Tagore, y de ello ya he escrito in extenso en otro lugar (Santoyo, 2004). Pero merece la pena recordarlo de nuevo aquí, porque creo que el caso responde bien a la intención de esta pregunta.
Tagore, 1861-1941, autor de una amplísima obra literaria en lengua bengalí, no comenzó a traducirla al inglés hasta cumplidos los cincuenta años, cuando en mayo de 1912 embarcó en Bombay rumbo a Londres, y para entretener el tiempo durante la larga travesía se dedicó a verter al inglés algunos de sus poemas. En noviembre de ese año ya salió de imprenta el primero de sus textos autotraducidos, Gitanja$l i$, con prólogo de Yeats; eran, se lee en porta$\mathrm{da}$, "prose translations made by the autor from the original Bengali". El éxito editorial fue enorme: diez ediciones el primer año a la venta. Siguió un segundo poemario en octubre de 1913. Un mes más tarde, el 13 de noviembre de 1913, la academia sueca hacía público el Premio Nobel de Literatura: Rabindranath Tagore, concedido "because of his profoundly sensitive, fresh and beautiful verse, by which, with consummate skill, he has made his poetic thought, expressed in his own English words, a part of the literature of the West". Tan solo había transcurrido año y medio desde que el autor comenzara a traducir sus poemas. Era el primer hombre de letras no europeo que recibía tal distinción, y era la primera vez, y creo que la única, que el Nobel recaía, expresamente, en una obra autotraducida. Sorprendente todo ello. Con un epílogo que quizá nadie esperara, porque Tagore acabó arrepentido de haber autotraducido su obra, y en sus últimos años no cesó de lamentar haberlo hecho: en 1935, ya con 74 años, escribía (y repetía):

Me tentó una arriesgada aventura cuando puse mis manuscritos en manos de los editores ingleses...Ya no soy joven, y he tenido mucho tiempo para darme cuenta de lo poco o nada importante que es salir de la esfera natural de uno mismo para ganar cierto reconocimiento... Las lenguas son monarcas celosos, y rara vez expiden pasaportes a los viajeros que cruzan sus fronteras celosamente guardadas... He sido zafiamente injusto con mis creaciones originales, en parte por mi propia incompetencia y en parte por negligencia..., he sido injusto conmigo mismo y con el templo de la Musa que, orgullosa, re- 
clama flores de su propio clima y cultura... (trad. J. C. Santoyo)

RG/MLS: Un primer hito en los estudios sobre la autotraducción fue el número temático de la revista Quimera (2002). ¿Cómo ve el camino recorrido desde entonces? ¿Cuáles son los enfoques que más han cambiado? ¿Cuáles son las áreas que quedan por explorar?

JCS: Apostilla inicial sobre la revista Quimera: El tema autotraducción comenzó a despertar interés en España e Hispanoamérica hace poco menos de treinta años, en el decenio de los 90 del pasado siglo xx. Gota a gota, casi no hay otro modo de decirlo, comenzaron a publicarse aquí y allá distintos ensayos, breves en general y de carácter un tanto tentativo, como fueron en España, por ejemplo, sendos artículos de N. Carpintero y G. Cuadrado sobre la autotraducción en la ciencia y la tecnología (1994), de Pilar Blanco sobre Mistral, y de M. D. Díaz Palacios sobre Jorge Semprún (1995), o los tres ensayos iniciales de Helena Tanqueiro (1997-2000); y en Argentina: "Stirring Still: De la autotraducción y otras cuestiones", de María Inés Castagnino, en 1997, y "Los alcances de la autotraducción", de Laura Cerrato, en 1999.

El número 210 de Quimera: Revista de Literatura, enero de 2002, fue un hito en el mundo lector de su tiempo (y de ahí que muchos guardemos aquel ejemplar) por un doble motivo y acierto: en primer lugar, por haber sabido detectar aquel disperso e inquieto renacer de la autotraducción, hasta entonces prácticamente desconocida de los lectores; en segundo lugar, por haberle dedicado un número monográfico justo en el momento en que ese tema eclosionaba, trasladándolo, digámoslo de la forma más gráfica posible, de la universidad al quiosco (sin demérito para los quioscos), y convirtiéndolo en tema y materia de interés general y, por lo tanto, de investigación.

Como conviene dar al César lo que es del César, etc., he de recordar también que Quimera ya había sido precedida por dos revistas europeas: una en Viena, en 1996, Quo vadis, Romania, $\mathrm{n}^{\circ} 7$, con el monográfico "Übersetzen und Selbstübersetzen", otra en Florencia, Semicerchio, $\mathrm{n}^{\circ}$ 20-21, a su vez con el monográfico "La lingua assente: Autotraduzione e interculturalità nella poesía europea."

\section{RG/MLS: ¿Cómo ve el camino recorrido desde} entonces?

JCS: Es evidente que la evolución vivida por los estudios de autotraducción en los últimos decenios ha sido tan rápida que uno piensa si no habrá llegado ya el momento de echar el freno, volver la vista atrás y repensar lo hecho hasta ahora, de cara al futuro. Es innegable que en ese breve camino recorrido se han cubierto, al menos en parte si no en todo, muchos y distintos ámbitos: la compleja tipología de esta práctica traductora, su creciente desarrollo histórico hasta nuestros días, sus relaciones interdisciplinares, también las que se dan entre bilingüismo, diglosia y autotraducción, el análisis contrastivo de un buen número de textos, las implicaciones sociológicas, culturales, editoriales, etc. Y además se han desmentido también 'verdades' que no lo eran y que llevaban largo tiempo admitidas como tales.

Lo cierto es que desde hace unos treinta años la autotraducción ha despertado un sorprendente interés en muy distintas parcelas de los estudios humanísticos (teóricos, históricos, contrastivos, etc.). Como de ello hay pruebas más que suficientes, elegiré una bien objetiva, que creo también significativa: el número de tesis doctorales sobre autotraducción, de las que se encuentra una relación, hasta 2020, en la bibliografía que desde hace años viene compilándose en internet, hoy bajo la dirección de la Dra. Eva Gentes. Entre 1975 y 2000 (25 años) se defendieron seis tesis doctorales sobre autotraducción, en cuatro países: Austria (Universidades de Viena y Graz), EE.UU. (Vanderbilt University y Chicago), Alemania (Freiburg) y España (Barcelona); en el siglo XXI, entre 2001 y 2020 (20 años), se defendieron 
70 tesis doctorales, con picos de siete tesis en 2017 y ocho tesis en 2018; y hay constancia y documentación de otras ocho tesis en preparación; imposible detallar aquí las universidades en que se han presentado, pero sepa el lector que van desde Tokio, Buenos Aires y Oxford a universidades de São Paulo, Edimburgo y Ciudad del Cabo. Aprecie el lector la diferencia y saque sus propias conclusiones sobre la rápida evolución de esta nueva parcela de los estudios de traducción. Si ya estos últimos han sido los que más desarrollo han experimentado en el área de las humanidades, similar y casi paralelo en su evolución al de los estudios de informática (quizá porque unos y otros partían de cero), tal desarrollo ha sido aún más rápido en lo que concierne a los estudios de autotraducción.

RG/MLS: ¿Cuáles son los enfoques que más han cambiado?

JCS: Desde la distancia que da el paso del tiempo, incluida en ella la propia experiencia, dos son los cambios mayores que con respecto a la autotraducción aprecio en los últimos, digamos, cuarenta años, de 1980 a 2020.

El primero, la propia condición de la autotraducción como objeto de estudio. Hace tan solo cuarenta años, en los 80 y 90 del siglo pasado, la autotraducción no existía, o casi. Recuérdese que para Antoine Berman las autotraducciones no eran sino excepciones (1984, p. 14) y para Brian T. Fitch, un fenómeno raro (1993, p. 127). Hoy en día nadie sostiene ya tales opiniones, porque la autotraducción ha pasado de la nada, o casi, a un primer plano del interés traductológico, y ello por tratarse de un fenómeno que resulta ser universal. Baste un repaso a la amplísima bibliografía (libros, tesis doctorales, artículos, capítulos de libros, congresos, revistas, etc.) que coordina la doctora Eva Gentes, ya citada, para apreciar en su justa medida el enorme cambio experimentado. A su vez, cuando echo un vistazo al catálogo-fichero de autotraductores que vengo elaborando y compruebo que su número se acerca a los mil quinientos, de todos los países y desde el siglo I al siglo XXI, lo de rarísimos, o lo de excepciones, me suena ya a música celestial.

Con todo, considero que el cambio mayor ha sido el paso dado de lo particular a lo general, o, por hablar en términos de botánica y zoología, el paso del individuo a la especie. Lo que necesita, creo, cierta explicación. Cronológicamente, buena parte de los primeros, segundos y terceros trabajos sobre la autotraducción no lo han sido sobre la 'especie', sino sobre el 'individuo'; lo han sido sobre este autotraductor o sobre esa obra autotraducida. Era el 'individuo', el caso particular, lo que interesaba. Y lo que se obtenía era, en palabras de Rainier Grutman, una galería de retratos, que estaba bien, y hasta muy bien, pero que contaba, hay que admitirlo, con un horizonte epistemológico limitado. Yo mismo he vivido esa evolución, quizá por eso la conozco bien. Durante varios años mi interés se centró en las versiones que de su propia obra habían hecho, pongamos por caso, Sabine S. Ulibarri, Rosario Ferré, Aitmatov, Tagore, Ariel Dorfman o Francisco Martínez de la Rosa. Pero desde hace aproximadamente un decenio he venido dejando de lado el caso particular, este o aquel texto autotraducido, este/a o aquel/ la autotraductor/a para ocuparme del fenómeno autotraductor per se. He ido así dando a la imprenta títulos como "On Mirrors, Dynamics and Self-Translations", en 2013 (Santoyo, 2013a), luego en 2015 "Consideraciones a propósito del estatus de la autotraducción en la Península Ibérica" (Santoyo, 2015), etc. Es una evolución personal, indudablemente, pero veo que ha sido y está siendo parecida o muy semejante en otros colegas.

$R G / M L S: ¿ C u a ́ l e s$ son las áreas que quedan por explorar?

JCS: La pregunta es compleja y la respuesta, difícil. Supongo que si se la hacen a diez estudiosos de la autotraducción las contestaciones serían todas distintas. Personalmente no creo que haya una única dirección hacia la que dirigirse, $\mathrm{y}$, aun 
así, Dios me libre de decir a nadie por dónde se ha de seguir caminando en esta senda. Los frentes abiertos son muchos, y más en una disciplina de llegada tan reciente al mundo académico que muchos somos aún testigos directos de haberla visto nacer. Me limitaré, por prudencia, a apuntar tres parcelas en las que a mi me gustaría seguir trabajando, si los años fueran clementes, y en los que, cómo no, me gustaría que también otros lo hicieran.

[a] Complementariedad. Algo que siempre me ha fascinado, pero en lo que no he tenido ocasión de ahondar, es la naturaleza de la relación final entre original y texto autotraducido. El DRAE define 'complemento' como la "cosa, cualidad o circunstancia que se añade a otra para hacerla íntegra o perfecta". Es el caso de la autotraducción, texto 'añadido' al original, que lo complementa y completa. Pero ¿se trata ya de una o de dos obras distintas? Porque el hecho es que en la autotraducción el original y el texto traducido son dos facetas inseparables de la obra, cara y cruz de una sola y única moneda, en un estatus de entretejida textualidad: cara y cruz investidas ambas con lo que en 1988 Brian T. Fitch denominó authorial intentionality, algo que se les niega a las versiones hechas por mano ajena.

El autotraductor ha repensado su obra en otro idioma, en otro momento (habitualmente posterior) y quizá (no; seguro) en el proceso ha optado por soluciones textuales distintas de las originales. La autotraducción proporciona una segunda visión del mismo texto, no opuesto o enfrentado a él, sino complementario de él. Por eso, cuando no existe el original, porque se ha perdido, el texto autotraducido asume a todos los efectos la condición de original, que tal es el caso, en 1457, del original en latín de la alegoría política de Alfonso de Palencia Batalla campal de los perros contra los lobos, de la que solo sobrevive la autotraducción al castellano; o el caso de Richard Cantillon, economista irlandés, que alrededor de 1720 escribió un Essay on Economic Theory (original hoy perdido), que el propio autor tradujo al francés con el título de Essai sur la nature du commerce en général, que es la versión que hoy en día se sigue editando.

Complementariedad que llega - es el límitehasta la más perfecta unión que puede darse entre original y traducción: la intratextual: una indisoluble unidad, casi hipostática, que se alcanza en textos en los que original y traducción son una única unidad textual en dos lenguas entrelazadas. Como una moneda con las dos caras a la vista, en la que cualquiera de ellas puede ser la cara o la cruz, indistintamente. Recuérdese el poema de Alastair Reid "Lo que se pierde / What Gets Lost":

I keep translating traduzco continuamente entre palabras words que no son las mías into other words which are mine de palabras a mis palabras.

Y, finalmente, ¿de quién es el texto?

Who do words belong to?

Del escritor o del traductor writer, translator o de los idiomas or to language itself ? [...]

[b] Cartografia histórico-geográfica de la autotraducción. Años atrás, allá por mayo de 2004, expuse yo en Winnipeg, los muchos espacios en blanco (blank spaces) que aún quedaban por cubrir en la historia de la traducción. Uno de ellos, el de la propia historia de la autotraducción: "Another vast territory without history is self-translation", y daba allí razones y motivos para pensar así. Años después, ya en 2013, publiqué un "Esbozo de una historia de la autotraducción" (Santoyo, 2013b), tan esbozo, apenas trece páginas, que yo mismo reconocía que era una historia "trazada a grandes líneas, casi a brochazos". Poco han cambiado las cosas en los últimos años, al menos en lo que a mí se me alcanza.

"Self-translation is a much more widespread phenomenon than one might think", reconocía Christopher Whyte en 2002 (p. 64). Sí, pero ¿sabemos qué alcance real tiene el término widespread, o solo lo suponemos? Porque creo que no me equivoco si digo que en esta parcela queda mucho, quizá demasiado, por hacer, porque son muchos 
los blank spaces en el tiempo y en el espacio que aún hay en el panorama de la autotraducción. Apenas sabemos nada (o yo al menos nada sé, o muy poco) de grandes parcelas de la historia de la autotraducción, por ejemplo, durante los mil años que duró el imperio bizantino (quién, qué textos, entre qué lenguas, etc.); o el papel desempeñado por la autotraducción en el ámbito científico, ya desde el siglo XI con la figura de Abu Raihan al-Biruni.

Tarea también pendiente es la 'des-occidentalización' de la historia de la autotraducción (como de la historia de la traducción en general). Abundan ya los estudios sobre la autotraducción en Occidente, en épocas varias de Francia, España, Italia, Canadá, Bélgica y Países Bajos, Estados Unidos y -en menor medida- América Latina. Pero es muy poco lo que aún se sabe de la autotraducción en el mundo islámico, en el sudeste asiático de nuestros días, en Japón, China o la India (a pesar de los numerosísimos autotraductores que ya desde el siglo XIX se registran en este país)...

[c] Tipología. No creo que se haya ahondado aún lo suficiente en la naturaleza del proceso autotraductor. Puede este, en principio, mostrarse particularmente simple, pero el análisis más somero ya demuestra que se trata de un fenómeno en extremo complejo, que ofrece una amplia gama tanto de modalidades inter- $y$ endo- lingüísticas como de estrategias de traducción y resoluciones textuales. Intentos ha habido algunos de dar cierta sistematización a esa variedad, aunque en mi opinión han sido parciales y de limitado alcance. Distintas propuestas tipológicas llevan la firma, entre otros, de Grutman (1998), Oustinoff (2001) y Ramis (2011, si bien cabe señalar que este ofrece un 'tipología de los autotraductores', no de autotraducciones). Como en los dos temas anteriores, también en este di yo unos primeros pasos hace casi diez años, en un intento de abordar con detalle la variada casuística que a lo largo de los siglos presenta el proceso autotraductor. Solo en parte lo conseguí. Al término de aquellas páginas escribía yo, a guisa de consciente disculpa: "Ni mucho menos he pretendido agotar el tema de la tipología autotraductora: tan solo ofrecer un ensayo, o lo que es lo mismo, un primer intento clarificador: aquí lo dejo, a la espera que alguna otra pluma, con más tiempo y dedicación, complete, corrija y perfeccione estas páginas". Afortunadamente así ha sido. Nuevas dicotomías y términos más precisos se han venido añadiendo a los ya recibidos: autotraducción transparente/opaca, semiautotraducción (Dasilva); vertical/horizontal (Grutman); directa/indirecta (Manterola Agirrezabalaga); etc.

Pero campo queda aún por explorar..., y entre esas exploraciones una que nunca he tenido tiempo de abordar, aunque ganas no me han faltado: la de los paratextos en la autotraducción; ya es sabido, Gérard Genette, etc.

RG/MLS: En un artículo que publicó en 2015 usted señala que comparte la opinión de Xosé Manuel Dasilva (2013) respecto de "la existencia de una autotraductología ibérica como posible disciplina de perfiles propios" (Santoyo, 2015, p. 162). Nos gustaría consultarle si considera que en América Latina se da un fenómeno similar al constatado en la Península Ibérica en materia de autotraducción.

JCS: Sí y no. Y me explico. Desde un punto de vista autotraductor, el caso de la Península Ibérica es muy particular, precisamente porque cuenta con perfiles propios. En un territorio geográficamente tan reducido como el de España la historia ha querido que estén vivas al menos cuatro lenguas: castellano, catalán, gallego y vasco (a las que habría que añadir el asturiano y el aragonés, pero sobre esto hay discrepancias). España es también uno de los países del mundo donde más libros se traducen, y ello por dos distintas vías: la extra- o ultra- peninsular (de lengua extranjera a una de las cuatro lenguas peninsulares, o viceversa) y la intrapeninsular (de una a otra lengua peninsular, por ejemplo: catalán > castellano/vasco/gallego, o vasco $>$ castellano/catalán/gallego). 
Ha habido y hay casos, muy numerosos, de autores españoles que han traducido su obra del primer idioma en que la escribieron a una segunda lengua, esta extranjera, o viceversa, y baste recordar en el siglo xx a Ramiro de Maeztu (de/al inglés), a Juan Larrea y a Jorge Semprún (de/al francés) y a Salvador de Madariaga (de/al francés, y al inglés). No es esa la vía que ahora nos ocupa. Porque donde ha florecido la autotraducción de forma extraordinaria ha sido en las versiones intrapeninsulares. Es frecuente, de hecho es muy frecuente, que un autor catalán o gallego o vasco traduzca su(s) obra(s) al castellano, y ello desde siglos atrás, aunque nunca tanto como desde hace cien años. Autotraductores intrapeninsulares de nombres bien conocidos han sido o son, por ejemplo, Rosalía de Castro, Álvaro Cunqueiro y Manuel Rivas desde el gallego, Baltasar Porcel, Carme Riera y Joan Margarit desde el catalán y Gabriel María Aresti, Nicolás Ormaechea 'Orixe' y Bernardo Atxaga desde el vasco. El corpus textual autotraducido es en estos momentos amplísimo y de casuística muy variada, las situaciones de diglosia son distintas en Cataluña, en Galicia y en el País Vasco, y distinta también la sociología lingüística en la que esas autotraducciones se generan. Nada extrañan, pues, comentarios como este de Aina Monferrer:

La península Ibèrica és un dels principals centres neuràlgics de l'autotraductologia literària per motiu de les relacions multilingües que s'hi desenvolupen, brou de cultiu especialment prolífic per a aquest tipus especial de traduccions $(2015$, p. 254).

En una situación así es incuestionable la amplitud del campo de estudio que se le ofrece al investigador: análisis y descripción de los procesos autotraductores entre los varios idiomas peninsulares y en todas sus facetas (teoría, casuística, descripción, sociología, historia, etc.), lo que, precisamente por sus perfiles propios y distintos, nos permitiría hablar de una autotraductología ibérica; más aún si en el calificativo incluimos, en puro contraste, un caso tan diferente como el portugués, en el que las autotraducciones son tan escasas que casi es necesario buscarlas con candil. Una autotraductología ibérica que, por cierto, y además, cuenta ya con un notable plantel de estudiosos, entre los que destacaría a Xosé Manuel Dasilva en el ámbito de la lengua gallega, a Josep Miquel Ramis en el de la catalana y a Elizabete Manterola Agirrezabalaga en el de la vasca, por solo citar tres nombres (con disculpas a los muchos no citados).

Puedo estar equivocado, pero creo que en todo el continente americano, de norte a sur, no se da una situación semejante a la española que pudiera dar pie a pensar, en los mismos términos, en una autotraductología latinoamericana.

Dicho lo cual, y no obstante, creo también que en la actualidad se dan todas las condiciones para el desarrollo de una autotraductología latinoamericana, de perfiles propios, obviamente, y por lo tanto muy distintos de los que se dan en la Península Ibérica, pero tan válidos como estos últimos. Para explicar por qué lo creo así, vuelvo a un artículo mío, "Autotraducción y resurgimiento literario indígena en Hispanoamérica", que Lila Bujaldón de Esteves, Belén Bistué y Melisa Stocco tuvieron en 2019 la amabilidad de acoger en las páginas del libro Literary Self-Translation in Hispanophone Contexts: Europe and the Americas.

América (decía yo allí) es un continente plurilingüe: México cuenta con 62 lenguas indígenas; Paraguay es un país oficialmente bilingüe, español-guaraní; en Bolivia se siguen utilizando las lenguas indias, en particular el aymara y el quechua; otro tanto pude decirse de Ecuador; en Guatemala, donde el $80 \%$ de la población es india o mestiza, hay unas veinte lenguas aborígenes, la mayoría de origen último maya, entre ellas el quiché, el cakchiquel, el mam y el kekchí; Perú es un complejo mosaico de cuarenta y dos grupos etnolingüísticos, etc. En esas lenguas indígenas viene produciéndose desde hace algunos decenios un sorprendente resurgir literario, en el que es muy frecuente (yo diría que enormemente frecuente) que los 
autores escriban su obra en dos idiomas: por lo común, primero en su lengua nativa, para después - ellos mismos - traducirla al español: autores que se traducen porque son bilingües, porque, al escribir en lenguas minoritarias, no es nada fácil hallar traductores ajenos, y porque traducirse al español es abrirse a un público lector mucho más numeroso. Literaturas en dos versiones, paralelas y especulares, literaturas en autotraducción.

Es el caso de Chile, donde desde Poemas mapuches en castellano, de Sebastián Queupul, en 1966, un grupo significativo de autores ha comenzado a escribir en mapudungún $\mathrm{y}$, al mismo tiempo, a traducir su propia obra a la lengua dominante del entorno, el español. Paraguay cuenta desde hace casi cien años con una pujante literatura en guaraní, y con una larga lista de conocidos autotraductores al español. La literatura maya de Guatemala no comenzó a publicarse hasta los años 80 del pasado siglo, y lo fue sobre todo en ediciones bilingües que, por lo común, contenían originales en alguna de las varias lenguas locales (akateko, q'anjob'al, popti' o chuj, por ejemplo) y su correspondiente traducción al español, con frecuencia llevada a cabo por el propio autor. En México son tantos los autores que hoy están creando literatura en alguna de sus más de sesenta lenguas indígenas, y traduciendo a continuación su obra al español que no es este lugar para una mera relación de sus nombres: remito al lector al artículo citado. Baste decir que, en opinión de Gregorio Regino, "el surgimiento de esta literatura [indígena mexicana] es uno de los hechos más relevantes en la cultura de México del siglo XX" (Regino, 2005, p. 3). Podría seguir repasando situaciones análogas, como las de Nicaragua, Perú y Bolivia, pero no lo creo necesario.

Estas nuevas literaturas responden en términos generales (la mapuche o la maya son buenos ejemplos de ello) a tres parámetros claramente bien definidos: la oralidad — como tradición creativa-, la ruralidad - como fuente cultural- y la autotraducción al español — como forma de edición-. Llamativo resulta también que, al autotraducirse, los autores indígenas se instalan sobre la línea de frontera que hasta ahora ha separado sus dos lenguas - y sus dos culturas-; pero esa misma posición fronteriza se ha convertido en el escenario de una novedosa dialéctica transcultural (entre nosotros y ellos), y en el escenario, asimismo, de un diálogo de lenguas, de culturas y de sociedades en contacto; un diálogo del que cada autor, al traducirse a sí mismo, es único protagonista: de hecho, estamos ante un diálogo convertido en monólogo interior en dos idiomas y entre dos culturas. Algo ciertamente llamativo, por utilizar un término más bien neutro.

En una situación así es más que evidente (y suficiente) el campo de estudio que se le ofrece al investigador: ante sí tiene la posibilidad de analizar, describir y contrastar los distintos procesos autotraductores que se dan en unos y otros idiomas de América Latina, y en todas sus facetas (casuística, teoría, sociología lingüística, historia, etc.); lo que, precisamente por sus perfiles autóctonos y distintos (tan distintos de los de la Península Ibérica), nos permiten ya hablar, creo que también aquí sin exageración, de una autotraductología latinoamericana "como posible disciplina de perfiles propios", en la que tendrían cabida estudios de estrategias de traducción, géneros literarios, causas y motivaciones, límites de transferencia e intraducibilidades, procesos de recepción y edición, etc. Mimbres no han de faltar para trenzar con ellos un buen cesto.

Todo ello sin olvidar, naturalmente, la otra vía, parte ineludible de la misma traductología: las versiones a lenguas extranjeras que en Latinoamérica vienen llevándose a cabo ya desde el siglo XIX. Traductores de obra propia a un segundo idioma, casi siempre al inglés, francés o italiano, fueron el colombiano Miguel Antonio Caro, los peruanos José María Arguedas y César Moro, los chilenos Vicente Huidobro y María Luisa Bombal, el cubano Guillermo Cabrera Infante, el brasileño João Ubaldo Ribeiro, la puertorriqueña Rosario Ferré y un largo etcétera... Pienso en un único país, 
Argentina, pongamos por caso, y a mí acuden títulos de las obras autotraducidas por Manuel Puig, Juan Rodolfo Wilcock, Alfred Ébelot, Silvia Baron Supervielle, Beatriz Badikian, Alicia Borinsky, Ariel Dorfman, Juan Gelman, Marcelo Lobera, Carlos Sánchez..., ¿cuántos más?

RG/MLS: ¿Qué aportan nuestras investigaciones sobre la autotraducción al conocimiento en materia de traducción? En un plano más global, quisiéramos saber qué opinión le merece la denominación inglesa 'self-translation studies'. ¿Estamos en condiciones de hablar de una (sub)disciplina dentro de la traductología?

JCS: (a) Respondo a las dos últimas preguntas, porque creo que se solapan, al menos en intencionalidad, y respondo en sentido inverso.

No me cabe la menor duda de que estamos en condiciones de hablar de una subdisciplina dentro de la traductología, y subrayo: dentro de ella. Porque de lo que hablamos es, en definitiva, de traducción. De una variante muy particular, pero de traducción. Y subdisciplina, porque la autotraducción cuenta ya con un marco conceptual propio, distinto del generalista, y con suficiente individualidad respecto a las restantes parcelas de los estudios de traducción como para mantener dentro de ellos un carácter propio: una bitextualidad de autor/auctoritas único/a, un amplísimo corpus textual propio y característico, numerosa bibliografía específica, considerable discurso teórico, y todo ello a pesar del breve tiempo transcurrido desde que naciera como objeto de estudio.

En cuanto a la denominación, self-translation studies, quizá haya que dejar pasar el tiempo y ver cuál acaba cuajando. Ya ha ocurrido antes: a finales de los años 60 del pasado siglo se habló de The Science of Translation (Bausch et al., 1972); en los años 70 y 80 Brian Harris, en Canadá, y Jean-René Ladmiral y Antoine Berman, en Francia, apostaron por el término traductología para lo mismo que James S. Holmes en 1972 y luego Gideon Toury denominaron translation studies. Tanto monta, monta tanto. Hoy en día estas dos últimas formas son de uso equivalente, y hasta conveniente como sinónimos. Digamos que, en lo que a mí me atañe, me agrada la expresión self-translation studies / estudios de autotraducción, quizá porque la encuentro académicamente menos pretenciosa que otras que se me puedan ocurrir. Pero como casi todo, también esto es opinable.

(b) ¿Qué aportan nuestras investigaciones al conocimiento en materia de traducción?

Aportan, sobre todo, un nuevo y novedoso capítulo a los estudios de traducción, inexistente, como ya he indicado, en los tratados de esta disciplina hasta finales de los 90 del pasado siglo y primeros años del actual. Hasta esos años cualquier tratado de traducción, pongo por caso Übersetzungswissenschaft: Probleme und Methoden, de Wolfram Wilss (Stuttgart, 1977), o, en España, el grueso volumen de Amparo Hurtado Albir, Traducción y traductología (Madrid 2001), estaba construido sobre tres pilares básicos: 1. un texto original en la lengua $\mathrm{A}$, 2. un agente traductor y 3. un texto traducido en la lengua B. De los tres, el pilar clave, el eje central en torno al que todo giraba, era el traductor, cuyos requisitos y competencias lingüísticas, textuales, culturales, de tema, de transferencia y demás debían garantizar el buen resultado del trasvase textual; él era el factor que debía saber y saber hacer; y desde mediados del siglo xx el que había que formar para una profesión. Las 'culpas', cuando las había, no podían caer sobre el texto origen ni sobre el texto meta, inertes ambos: solo sobre el agente traductor, causante único de lo bueno, lo regular y lo malo que el crítico hallara en el texto meta. Muchos, si no la mayoría, de los manuales de estudios de traducción que veo en mi biblioteca son desarrollos más o menos amplios de estas pocas líneas anteriores.

Pero llegaron los estudios de autotraducción $y$, en cierta manera, lo trastocaron todo. El esquema básico seguía siendo el mismo: seguía habiendo una lengua $A$, una lengua $B$ y un eje 
central, el autotraductor, pero un eje que había cambiado no solo de posición, sino también de naturaleza, porque contaba con poderes especiales: era también el autor del texto A. Y esos poderes lo cambiaban todo, incluida la condición del texto traducido, que pasa de ser un texto subordinado, secundario y suplente, a ser, de nuevo, un original.

En resumen, y por no alargarme más: eso es lo que nuestras investigaciones han aportado al conocimiento en esta materia: la apertura de una nueva (ya no tan nueva) ventana en los estudios de traducción, y a través de ella la contemplación de un paisaje de fondo que se nos ofrece dilatado, frondoso y por demás interesante.

RG/MLS: En El delito de traducir usted afirma no comprender "cómo las cárceles y juzgados [...] no están llenos de traductores (1996, p. 17). ¿Podría aplicarse la etiqueta delito también a la autotraducción? En caso afirmativo, ¿hasta qué punto y con qué reservas?

JCS: Antes de contestar a su pregunta, una puntualización, que, aunque algo extensa, creo necesaria. La cita sobre cárceles y juzgados pertenece a la tercera edición de El delito de traducir. La primera es de 1985, once años anterior, y era hija de su tiempo. Lo digo porque, a pesar de la omnipresencia del fenómeno traductor, cuando en los años 70 y primeros 80 uno recorría el panorama académico español en busca de algo de luz que le iluminara, nada encontraba sino tinieblas; miraras donde miraras solo había un horizonte más propio incluso de desierto que de páramo.

Esas eran las circunstancias en las que ha de situarse El delito de traducir, circunstancias que hasta cierto punto explican, o justifican, que por aquellas fechas el estado general de las traducciones, literarias o no, fuera en España crónicamente patológico, si bien ninguna crítica se alzaba denunciando tal estado, como no fuera la telegráfica coletilla final de alguna que otra reseña en periódicos y revistas. Los delitos a los que yo pude referirme en 1985 eran los de robo, malversación, manipulación, ignorancia, plagio, censura (propia y ajena), etc., habituales por aquellos años, y ya desde antiguo, en muchos de los textos traducidos, de los que el libro tiene más que suficientes ejemplos. Se plagiaban sin ningún pudor traducciones anteriores (varias de las ediciones españolas de Rebelión en la granja / La granja de los animales, de Orwell, son distintos plagios de la primera publicada en Argentina), se cortaban y cercenaban los textos a gusto del traductor o del editor, se cometían errores de bulto, y hasta de gran bulto, por desconocimiento del idioma extranjero, del propio o de ambos... Afortunadamente, hoy las cosas ya no son como eran, mucho han cambiado desde entonces, para mejor. Y la vanidad me lleva a creer que, aunque poco, aquel libro mío de 1985 algo pudo ayudar a concienciar a traductores y lectores de la necesidad de empezar a hacer las cosas mejor de lo que hasta entonces se hacían.

En cuanto a su pregunta (si podría aplicarse o no la etiqueta delito a la autotraducción), mi respuesta es clara y sin reservas: no, no podría aplicársele esa etiqueta. La raíz de las autotraducciones, su idiosincrasia, singularidad, excepcionalidad o comoquiera denominársela, lo que las caracteriza y define por encima de cualquier otro rasgo, es que en ellas el traductor es también el autor de la obra, a diferencia del resto de traducciones, en las que el traductor lo es de obra ajena. El traductor es únicamente dueño de sus propias palabras (para bien o para mal), pero no lo es del original del que derivan, al que debe fidelidad (entiéndase esta como se entienda); en cambio, el autotraductor es dueño de sus propias palabras y también del original del que derivan, es autor de unas y de otro, y como tal, autor-dueño de unas y de otro. Si un autotraductor suprime en su versión un párrafo, o todo un capítulo, o lo cambia añadiendo, modificando o quitando materia textual, suyos son ambos textos: la fidelidad debida ya no lo es a una obra ajena, sino a la obra propia, sobre la que puede ejercer todos sus derechos de autor, incluidos los de cambio, alteración, supresión, etc. El delito 
en obra ajena deja de serlo en obra propia, porque en estos casos prima la auctoritas sobre la fidelitas... "What is wonderful about self-translation —dejó escrito Robert Wechsler (1998, p. 214) - is that it allows the translator to take any liberties he feels like taking".

Claro que entonces la aproximación teórica al concepto de traducción ha de ser bajo supuestos ciertamente diferentes de los aplicados a textos vertidos por mano ajena. Porque las traducciones de autor operan y se asientan en los límites de, incluso al margen de, buena parte de los supuestos y presupuestos teóricos de la disciplina que conocemos como estudios de traducción: así, adecuación, equivalencia y fidelidad, por ejemplo, son términos con definiciones que pueden no encajar ya, y de hecho no encajan, ni en la teoría ni en la práctica de lo que denominamos autotraducción. Pero esa ya es otra historia.

\section{Referencias}

Berman, A. (1984). L'Épreuve de l'Étranger. Culture et traduction dans l'Allemagne romantique. Gallimard.

Dasilva, X. M. (2013). Estudios sobre la autotraducción en el espacio ibérico. Peter Lang.

Fitch, B. T. (1988). Beckett and Babel: An investigation into the status of the bilingual work. University of Toronto Press.

Fitch, B. T. (1993). Beckett's literary cathedrals: Speculation on Beckett's achievement as a writer of prose fiction. Samuel Beckett Today / Aujourd'hui, 2, 125-132. https://www.jstor. org/stable/25781158

Monferrer, A. (2015). Reseña de Josep Miquel Ramis, Autotraducció: De la teoria a la pràctica. Caplletra, 59, (otoño, Valencia), 254-258. https://ojs.uv.es/index.php/caplletra/article/ view/6914/6821
Oustinoff, M. (2001). Bilinguisme d'écriture et auto-traduction. Julien Green, Samuel Beckett, Vladimir Nabokov. L'Harmattan.

Regino, J. G. (2005). Las lenguas indígenas en la literatura mexicana. http://interbilingue.ajusco. upn. $\mathrm{mx} /$ modules.php? name $=$ News $\&$ file $=$ ar ticle\&sid $=213$

Santoyo, J. C. (1996). El delito de traducir. Universidad de León.

Santoyo, J. C. (2004). Rabindranath Tagore: memorias de un autotraductor arrepentido. En F. J. Díaz Pérez y A. M. Ortega Cebreros (Eds.), $A$ world of English, $A$ world of translation: estudios interdisciplinares sobre traducción y lengua inglesa (pp. 155-191). Universidad de Jaén.

Santoyo, J. C. (2013a). On mirrors, dynamics \& self-translations. En A. Cordingley (Ed.), Self-Translation: Brokering originality in hybrid culture (pp. 27-38). Continuum.

Santoyo, J. C. (2013b). Esbozo de una historia de la autotraducción. En C. Lagarde \& H. Tanqueiro (Eds.), L'autotraduction aux frontières de la langue et de la culture (pp. 23-35). Éditions Lambert-Lucas.

Santoyo, J. C. (2015). Consideraciones a propósito del estatus de la autotraducción en la Península Ibérica. Glottopol: Revue de Sociolinguistique en ligne [Université de Rouen], 25 (enero), 47-58.

Santoyo, J. C. (2019). Autotraducción y resurgimiento literario indígena en Hispanoamérica. En L. Bujaldón de Esteves, B. Bistué, \& M. Stocco (Eds.), Literary self-translation in Hispanophone contexts: Europe and the Americas (pp. 23-47). Palgrave-Macmillan.

Wechsler, R. (1998). Self-Translation. Performing without a stage: The art of literary translation (pp. 213-216). Catbird Press.

Whyte, C. (2002). Against self-translation. Translation and Literature, 11(1), 64-71.

Young, H. T. (1995). The invention of an Andalusian Tagore. Comparative Literature, 47(1) (invierno), 42-52. 


\section{Apéndice: Bibliografía de Julio-César Santoyo sobre la autotraducción}

2001. Literatura chicana y traducciones de autor: Primeras consideraciones. En Federico Eguíluz et al. (Eds.), Aztlán: Ensayos sobre literatura chicana (pp. 243-256). Vitoria: Universidad del País Vasco.

2002. El reto del trasvase cultural: Cuando el autor es también el traductor. En Isabel Cómitre Narvaez \& Mercedes Martín Cinto (Eds.), Traducción y cultura: El reto del trasvase cultural (pp. 143-168). Málaga: Libros Encasa Ediciones y Publicaciones.

2002. Traducciones de autor: Una mirada retrospectiva. Quimera: Revista de Literatura [Barcelona], 210 (enero), 27-32.

2003. Rosario Ferré: Entre dos lenguas, entre dos culturas. En Pilar Abad García \& José Ramón Fernández Suárez (Eds.), Estudios de filología inglesa: homenaje al profesor José María Ruiz Ruiz (pp. 337-352) Valladolid: Universidad de Valladolid.

2003. De Nebrija a sor Juana Inés de la Cruz: Apuntes someros para una historia de las traducciones de autor (autotraducciones) en España y Portugal, 1488-1700. En José Antonio Sabio Penilla \& María Dolores Valencia (Eds.), Seis estudios sobre la traducción en los siglos XVI $y$ XVII (pp. 1-49), Granada: Editorial Comares.

2004. Self-Translation: Competence revisited (and performance as well). En Eberhard Fleischmann, Peter A. Schmitt \& Gerd Wotjak (Eds.), Translationskompetenz (pp. 223-235). Tubinga: Stauffenburg Verlag Brigitte Narr.

2004. Rabindranath Tagore: Memorias de un autotraductor arrepentido. En Francisco Javier Díaz Pérez \& Ana María Ortega Cebreros (Eds.), A world of English, a world of translation: estudios interdisciplinares sobre traducción y lengua inglesa (pp. 155-191). Jaén: Universidad de Jaén. Reeditado en: J. C. Santoyo (2008). Historia de la traducción: Nuevos y viejos apuntes (pp. 287-312). León: Universidad de León.

2005. Autotraducciones: Una perspectiva histórica. Meta, 50/3 (agosto), 858-867.

2006. Francisco Martínez de la Rosa, autor y traductor: Nueva visita a Aben Humeya. En Francisco Lafarga \& Luis Pegenaute (Eds.), Traducción y traductores: del romanticismo al realismo (pp. 463-488), Berna-Nueva York: Peter Lang. Reeditado en J. C. Santoyo (2008). Historia de la traducción: Nuevos y viejos apuntes (pp. 267-286). León: Universidad de León.

2006. Traducciones de autor (Self-Translations): Materiales para una bibliografía básica. Interculturalidad y Traducción, 2, 201-236.

2006. Blank spaces in the history of translation. En Georges L. Bastin \& Paul F. Bandia (Eds.), Charting the future of translation history. Current discourses and methodology (pp. 11-43). Ottawa: University of Ottawa Press.

2010. Translation and cultural identity: Competence and performance of the author-translator. Micaela Muñoz Calvo \& Carmen Buesa Gómez (Eds.), Translation and cultural identity. 
Selected essays on translation and cross-cultural communication (pp. 13-32). Newcastle upon Tyne: Cambridge Scholars Publishing.

2010. Autotraducciones intrapeninsulares: Motivos históricos, razones actuales. En Enric Gallén, Francisco Lafarga \& Luis Pegenaute (Eds.), Traducción y autotraducción en las literaturas ibéricas (pp. 365-380). Berna \& Berlín: Peter Lang. Reeditado en: Pilar Ordóñez López \& José Antonio Sabio Pinilla (Eds.) (2015). Historiografia de la traducción en el espacio ibérico: Textos contemporáneos (pp. 107-126), Cuenca: Ediciones de la Universidad de Castilla-La Mancha.

2011. La autotraducción intratextual. En Xosé Manuel Dasilva \& Helena Tanqueiro (Eds.), Aproximaciones a la autotraducción (pp. 217-230). Vigo: Editorial Academia del Hispanismo.

2012. La autotraducción en la Edad Media. En Marcial Rubio Árquez \& Nicola D`Antuono (Eds.), Autotraduzione. Teoria ed esempi fra Italia e Spagna (e oltre) (pp. 63-76). Milán: LED Edizioni Universitarie di Lettere Economia Diritto.

2013. On mirrors, dynamics \& self-translations. En Anthony Cordingley (Ed.), Self-Translation: Brokering originality in hybrid culture (pp. 27-38). Londres: Continuum.

2013. Esbozo de una historia de la autotraducción. En Christian Lagarde \& Helena Tanqueiro (Eds.), L'autotraduction aux frontières de la langue et de la culture (pp. 23-35). Limoges: Éditions Lambert-Lucas.

2013. Autotraducciones: Ensayo de tipología. En Pilar Martino Alba, Juan Antonio Albaladejo Martínez \& Martha Pulido (Eds.), Al humanista, traductor y maestro Miguel Ángel Vega Cernuda (pp. 205-221). Madrid: Dykinson DL.

2015. Consideraciones a propósito del estatus de la autotraducción en la Península Ibérica. Glottopol: Revue de Sociolinguistique en ligne [Université de Rouen], 25 (enero), 47-58.

2019. Autotraducción y resurgimiento literario indígena en Hispanoamérica. En Lila Bujaldón de Esteves, Belén Bistué \& Melisa Stocco, eds., Literary self-translation in Hispanophone contexts: Europe and the Americas (pp. 23-47 versión en español/pp. 49-74, versión en inglés). Cham, Suiza: Palgrave-Macmillan.

Cómo citar este artículo: Grutman, R. y Spoturno, M. L. (2022). Veinte años de estudios sobre la autotraducción: una entrevista con el profesor Julio-César Santoyo. Mutatis Mutandis, Revista Latinoamericana de Traducción, 15(1), 227-239. https://doi.org/10.17533/udea.mut.v15n1a13 